\title{
Serial-position curves in rats: Order memory for episodic spatial events
}

\author{
RAYMOND P. KESNER, MICHAEL O. MEASOM, SHAWN L. FORSMAN, \\ and TERRY H. HOLBROOK \\ University of Utah, Salt Lake City, Utah
}

\begin{abstract}
With the use of a recognition probe procedure, rats were trained to remember serial order of a four- or eight-item list (places on an eight-arm radial maze). The animals displayed a prominent "primacy" and "recency" effect, indicating a serial-position curve. The serial-position curve was more pronounced for the eight-item than for the four-item list. It is suggested that the "primacy" effect of serial-position curves is primarily a function of the utilization of controlled or effortful information processing. In addition, the data suggest a correspondence between animals and humans in the generation of serial-position curves for list learning.
\end{abstract}

In recent years there has been a concerted effort aimed at studying cognitive processes in animals. As a result, there has been an increased focus on the study of mnemonic function for multiple events that encompass list learning. When an animal is given a list of items, tests can be devised to determine whether it remembers item or serial-order information. Item information refers to information concerning the occurrence of an item, object, or event in the past. Order information refers to sequence information concerning the temporal-spatial order in which items or events have occurred. Most list-learning studies have investigated the ability of animals to remember whether an item in a list has been presented. However, very few studies have concentrated on whether animals can remember the order in which items have been presented. In a pioneering study, Shimp (1976) showed that pigeons have excellent memory for the order of occurrence of three items, with best performance primarily for the last of the three items ("recency" effect). However, when the first item was presented for a longer duration, significant increases in performance for the first item were found ("primacy" effect). This recognition probe procedure has advantages in that (1) the experimenter can determine the critical sequence of events, (2) memory for longer list lengths can be assessed, and (3) one can more easily assess performance as a function of serial position, and thus one might be able to generate a serial-position curve with both "primacy" and "recency" effects. In fact, preliminary data have been reported on a study using four rats and a serial-order memory recognition probe for an eight-item list length (Kesner \& Novak, 1982). In

Support for this research was provided by P.H.S. Grant NS 19406-01 and Biomedical Research Support Grant NIH RR 07092-13. We would like to thank David A. Huth, Department of Economics, University of Utah, and Davis Cope, Department of Mathematics, North Dakota State University, for their assistance in the statistical evaluation of the criterion data. Requests for reprints should be sent to Raymond P. Kesner, Department of Psychology, University of Utah, Salt Lake City, UT 84112. that study, animals were given a large number of trials, with each trial consisting of a study and a test phase. During the study phase, the animals were given access to eight arms (one at a time) in a specific sequence. The study phase sequences were varied from trial to trial. During the test phase (probe recognition), the animals were given a single test with a choice between two (first, middle, or last) previously visited arms. The correct response was to the arm that had been visited earlier in the sequence during the study phase of the trial. All four rats demonstrated a serial-position curve with excellent retention for the first ("primacy" effect) and last ("recency" effect) arms of the list.

The purpose of the present experiment was to replicate these findings, using more animals, two different training procedures, and list lengths of four and eight items.

\section{METHOD}

\section{Subjects}

Thirty-two male Long-Evans rats, weighing between 300 and $400 \mathrm{~g}$, were used. Each animal was individually housed and maintained at approximately $85 \%-90 \%$ of its free-feeding weight. The animal cages were kept in a laboratory with a 12-h light/dark cycle.

\footnotetext{
Apparatus

An eight-arm radial maze was used (see Olton \& Samuelson, 1976). It was painted white, was $94 \mathrm{~cm}$ in height, and was kept in a well-lit room with no windows, one door, and 10 calendar pictures placed around the room on the walls. The maze consisted of an octagonal central platform, $40 \mathrm{~cm}$ across, and eight arms, which radiated from it like spokes of a wheel. The arms were $71 \times 9 \mathrm{~cm}$ and were attached to the central platform with metal braces.

Each arm had 3-mm clear Plexiglas sides, which rose $5 \mathrm{~cm}$ above the surface of the arm and extended from the far end of the arm to $2.5 \mathrm{~cm}$ from the central platform. A food well, $2.5 \mathrm{~cm}$ in diameter, was drilled $1.5 \mathrm{~cm}$ deep at the far end of the arm. A $3-\mathrm{mm}$ Plexiglas guillotine door was located at the juncture between the platform and the arm. This door could be raised from below the maze surface. Each door was $10 \mathrm{~cm}$ wide and, when in the raised position, was $23 \mathrm{~cm}$ above the surface of the platform. By means of a series of pulleys and strings, each door could be raised and lowered from an adjacent lab room.

Strips of Plexiglas, $6 \times 18 \mathrm{~cm}$, were installed on the central platform in the gaps between the doors to prevent the rats from climbing between
} 
the doors. These strips, together with the doors, effectively formed a cylindrical Plexiglas chamber on the central platform; the animals could be placed into the chamber through the open top.

Finally, a piece of linoleum, $46 \times 150 \mathrm{~cm}$, could be wrapped around the central chamber in such a way that, when in place, the animal could see only the ceiling of the lab.

\section{Procedure}

Initially, using the Olton procedure (Olton \& Samuelson, 1976), all animals were trained until they had performed without errors on three of four consecutive trials. After criterion was reached, the Plexiglas doors were introduced such that admittance to any of the arms was controlled by the experimenter. The reinforcements, which consisted of one-quarter of a Froot Loop cerial piece, were available in the wells at the end of the arms. For three daily sessions, each rat was allowed to collect the reinforcements.

Finally, the actual serial-order probe training commenced. The training trials consisted of a study phase and a test phase. During the study phase, a sequence of eight arms was presented one arm at a time. Each study phase sequence was selected according to the stipulation that no three adjacent arms could be presented in one sequence. Moreover, the sequences were pseudorandom in that they could be used to test any one of the early, middle, or late positions for that trial. Thus, the animals could not predict which test position was to be selected. The study-phase sequences differed from trial to trial.

As soon as the animal returned to the central chamber from the last arm of a study-phase sequence, the linoleum cover was put into place around the Plexiglas chamber. The purpose of this cover was to demarcate the end of the study phase and the beginning of the test phase, as well as to prevent the rat from seeing the actions of the experimenter as he or she baited the correct test arm. Two of the doors previously visited were then lowered simultaneously. The animal could see which two doors had been lowered, because the linoleum was wrapped on the outside of the Plexiglas.

The selection of the two test doors depended upon which serial position was being tested on that trial and upon the rule that the two doors be either adjacent to each other or separated by only one door. On half of the trials, the correct response was to the right, and on the other half of the trials, the correct response was to the left.

Approximately $10 \mathrm{sec}$ after the lowering of the two test doors, the linoleum cover was removed and the subject was allowed to respond by entering one of the two open doors. The correct response was to the arm that had been visited earlier in the sequence during the study phase of the trial. If the animal made a correct response, it collected three Froot Loops from the well. If the animal made an error, it received no reinforcement and was not allowed to enter the correct door. Only one test was given for each study phase.

Thirty animals were trained on an eight-item list length. The animals received, on a random basis, a choice (one test only) of the first and second (1-2), fourth and fifth (4-5), or seventh and eighth (7-8) arms in the sequence. The animals were initially given eight trials per serial position for a total of 24 trials. One trial per day was given 5 days a week. If, after these 24 trials, the animal had not performed at $75 \%$ or better on tests of 1-2 ("primacy") and 7-8 ("recency") serial positions (criterion), then additional blocks of six trials (two trials per serial position) were given until the criterion was met for the most recent block of 24 trials or until a total of 100 trials had been given, at which time the training ceased for that animal.

Five animals did not reach criterion and were not included in the data analysis. Five of the $\mathbf{3 0}$ animals were first trained on a choice between the first and seventh arms in the sequence until they reached the criterion of 8 correct out of 10 responses. This was reached by all animals between 10 and 32 trials. The animals then received the same training as mentioned above.

Since the eight-arm list appeared to be a very difficult task, seven new animals were trained on a four-arm list (on the eight-arm maze). The same procedures were followed, but in this case the choices were between the first and second (1-2), second and third (2-3), and third and fourth (3-4) arm in the sequence.

\section{RESULTS}

The mean number of trials to reach criterion as a function of training procedure and list length is shown in Table 1. It can be seen that there were no differences in the mean number of trials to reach criterion. Statistical tests ( $t$ tests) failed to discover any significant effects among the groups.

The observed mean number of trials to reach criterion was 61.8. A probability analysis based on the assumptions that trials are independent and the outcome of each trial has an equal probability of an error or a correct response was performed to compare this observed value to those values expected on the sole basis of chance. Let $\mathrm{x}$ be the trial where exit criterion is met purely by chance; then $P(x)$ is the exact probability of exit on trial $x, \sum_{x=1}^{n} P(x)$ is the probability of exit on trial $n$ or less, and the expected mean number of trials to exit is $\sum_{x=1}^{\infty} P(x)$.

The probability analysis showed that for the animals to reach criterion for the eight-arm list by chance alone, an expected mean of 424 trials would have to be made. The probability of obtaining the criterion in 61.8 trials or less is .10 when based solely on chance.

There were five animals that did not reach criterion (i.e., 5 of 30), which would correspond to a .167 chance of not reaching criterion. This translates into an expected 246 trials based on chance $\left[\Sigma_{1}^{246} \mathrm{P}(\mathrm{x})=.623\right]$, or a .623 chance of reaching criterion. There is a significant difference between the observed (61.2) and expected (246) values $[t(24)=49.6, p<.0001]$.

Mean percent correct choices as a function of serial position for the eight-item list with or without pretraining is shown in Figure 1. The results indicate that for both training conditions there was a clear serial-position curve, with poor performance for the middle choice (4-5) in the list relative to good performance for the 1-2 position ("primacy") and the 7-8 position ("recency") within the list. A two-way repeated measures analysis of variance on the criterion data revealed that there was a significant serial-position effect $[F(2,46)=30.0, p<.001]$, but that there were no effects due to pretraining $[\mathrm{F}(1,23)<1$, $p>.10]$ or the interaction between serial-position effect and pretraining $[F(1,46)<1, p>.10]$. Additional Newman-Keuls tests revealed that performance for both

Table 1

Mean Number of Trials to Reach Criterion as a Function of Training Procedure and List Length

\begin{tabular}{|c|c|c|c|}
\hline & \multirow[b]{2}{*}{$\mathrm{n}$} & \multicolumn{2}{|c|}{ Number of Trials to Criterion } \\
\hline & & Mean & $\mathrm{SE}$ \\
\hline $\begin{array}{l}\text { 8-Arm List } \\
\text { Pretraining } \\
\text { 8-Arm List }\end{array}$ & 5 & 59.0 & 11.7 \\
\hline $\begin{array}{l}\text { No Pretraining } \\
\text { 4-Arm List }\end{array}$ & 20 & 61.8 & 3.8 \\
\hline No Pretraining & 7 & 68.5 & 4.5 \\
\hline
\end{tabular}




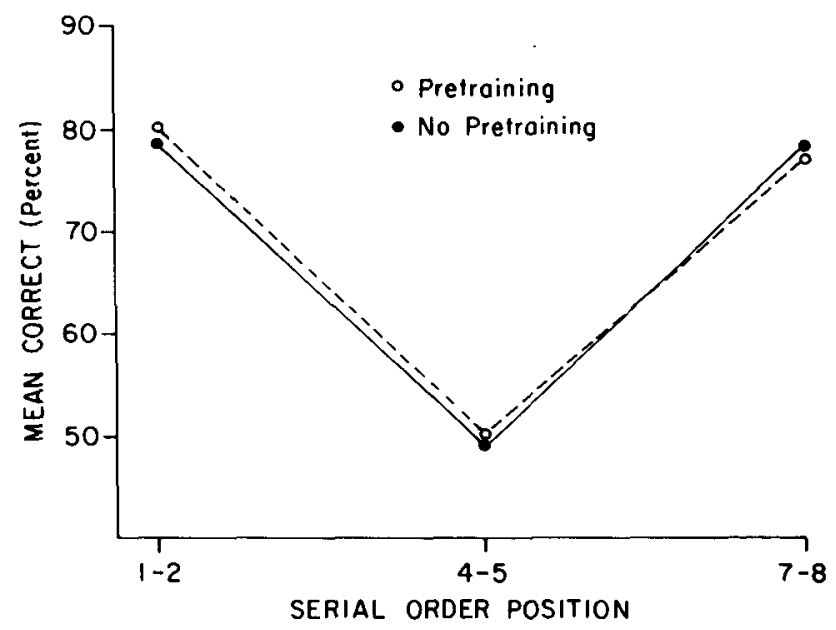

Figure 1. Mean percent correct performance as a function of serialorder position for an eight-item list (places on an eight-arm maze) under pretraining (tests on 1 vs. 7 choice) or no pretraining conditions.

the 1-2 and the 7-8 positions was significantly higher than performance for the $4-5$ position $(p<.001)$.

Mean percent correct choices as a function of serial position for the four-item list is shown in Figure 2. The results indicate good performance for every serial-order position. A one-way repeated measures analysis of variance on the criterion data revealed that there was a significant serial-position effect $[\mathrm{F}(2,12)=4.51, \mathrm{p}<.05]$. Additional Newman-Keuls tests revealed that performance for the 3-4 position was significantly better than performance for the $2-3$ position $(p<.05$ ), whereas performance for the 1-2 position was not significantly better than performance for the 2-3 position $(\mathrm{p}>.05)$.

\section{DISCUSSION}

The present results indicate that rats can remember the serial order of a list of items. The ability to learn serial order information for a list of items (places in a maze) was influenced neither by pretraining (the first and seventh item of the eight-item list) nor by item list length (four vs. eight items). Furthermore, for the eight-item list, the animals displayed good memory for early ("primacy") and last ("recency") items of the list and poorer memory for middle items of the list. Furthermore, it should be noted that order memory performance is stable past criterion, since sham-operated animals or animals with small cortical lesions continue to display both "primacy" and "recency" effects (Kesner \& Novak, 1982). The "same function was obtained for a four-item list, but in this case only the "recency" effect reached significance. These results represent a replication and extension of the data presented previously in a somewhat different context (Kesner \& Novak, 1982).

Furthermore, the results are consistent with a serialposition curve found for a three-item list in pigeons. It

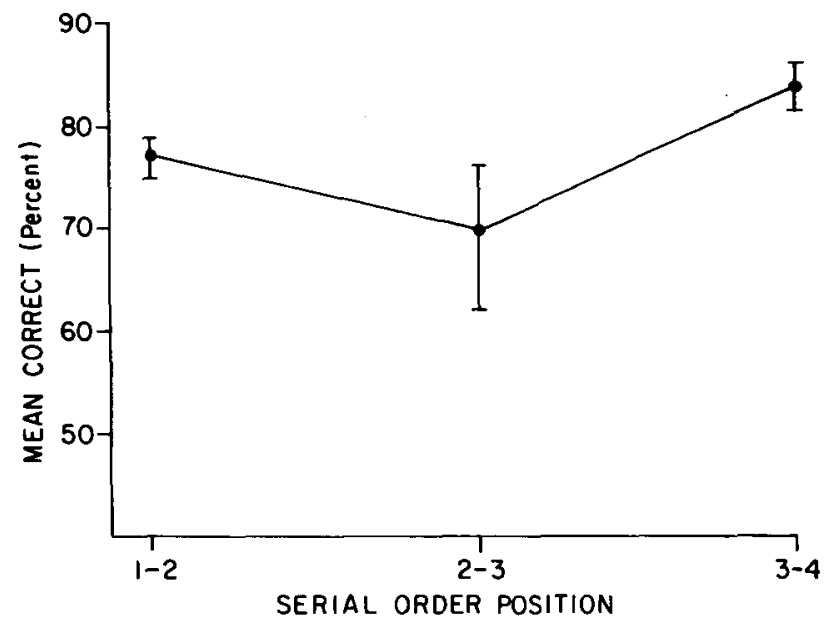

Figure 2. Mean percent correct performance as a function of serialorder position for a four-item list (places on an eight-arm maze). $I$ represents one standard error of the mean.

should be noted, however, that this was obtained only when the first item was presented for a longer duration (Shimp, 1976). The observation of a "primacy" effect is of real importance, because most studies using item-recognition tasks have found serial-position curves with only "recency" effects (Davis \& Fitts, 1976; Gaffan \& Weiskrantz, 1980; Olton \& Samuelson, 1976; Olton, Collison, \& Werz, 1977; Roberts \& Smythe, 1979; Thompson \& Herman, 1977; Whitlow, 1975). As a matter of fact, serial-position curves have been found in only a few studies using monkeys and rats (DiMattia \& Kesner, in press; Roberts \& Kraemer, 1981; Sands \& Wright, 1980). Because the classic serial-position curve is such a pervasive phenomenon of human memory (Donaldson \& Glathe, 1969; Glanzer \& Cunitz, 1966; Murdock, 1962, 1968; Norman \& Wickelgren, 1965), its elusiveness in animals is somewhat perplexing. Theoretical interpretations of the meaning of the serial-position curve have been based on (1) intraserial interference, (2) distinctiveness of positional stimuli, and (3) temporal structural analyses. Waugh (1960), following earlier contributions of Foucault (1928) and Melton (1963), has suggested that the "primacy" effect results from a lack of proactive inhibition on the initial list items, whereas the "recency" effect results from lack of retroactive inhibition on the terminal items. Murdock (1960) and Ebenholtz (1972) have suggested that the ends ("primacy" and "recency") of a list are more distinctive and therefore are remembered better than the interior positions. Clearly, different retrieval cues can operate on the distinctiveness of the end items (Tulving, 1968). Atkinson and Shiffrin (1968) have proposed that the "primacy" effect reflects information storage in longterm memory, whereas the "recency" effect results from the operation of a short-term memory buffer of limited capacity. Support for this latter position comes from the observation that a 10-min delay between the study and 
test phases disrupted the "recency" but not the "primacy" component of the serial-position curve (Kesner \& Novak, 1982).

Another possible explanation may be found by considering the distinction that has been drawn between automatic and controlled information processing (Hasher \& Zacks, 1979; Posner \& Snyder, 1975; Shiffrin \& Schneider, 1977). This conceptualization assumes that some information may be processed relatively automatically, requiring very little conscious effort. Other information, on the other hand, may be subjected to "controlled" (Shiffrin \& Schneider, 1977) or "effortful" (Hasher \& Zacks, 1979) processing, whereby learned routines for processing information are called upon as needed from storage in a long-term store. Unlike automatic processing, controlled processing requires much conscious attention. From the automaticcontrolled processing view, the suggestion arises that the "primacy" component of the serial-position curve might be present only if the mnemonic task places a sufficient load on the cognitive system to necessitate nonautomatic, effortful processing (Brown, 1974; Kinsbourne \& Wood, 1982). Kesner (1984) and Kesner and DiMattia (1984) have assumed that controlled processing can lead to more extensive and/or prolonged activation of active memory traces. Thus, a "primacy" effect appears because maintained or more extensive activation of the first items makes these items more available and perhaps more distinctive during the retention probe test.

The present data can be interpreted by any of the above theoretical interpretations of the serial-position curve. The observation of a more pronounced "primacy" effect for the eight-item than for the four-item list could be a function of greater utilization of controlled processes for the first item of the eight-item list. Given that controlled processing of information can produce more prolonged activation, there would be a higher probability of greater distinctiveness of the first item or there would be more transfer of critical information into long-term memory. Of those animals that reached criterion in less than 100 trials, there were no significant differences in the number of trials required to reach criterion. However, 5 of 30 animals in the eight-item list condition never reached criterion, whereas all animals in the four-item list condition reached criterion. It appears that the eight-item task is more difficult to learn, and thus the more pronounced "primacy" effect for the eight-item than for the four-item list would support the controlled-attention hypothesis. Shimp's (1976) results are also consistent with the attention-hypothesis interpretation in that the "primacy" effect observed only with increased exposure to the first item might have been due to the activation of controlled-attention processes.

In summary, it has been demonstrated that with the use of a retention probe procedure, rats can remember the serial order of a four- or eight-item list and display a serialposition curve that is the most pronounced for the eightitem list. These data suggest that there is a correspondence between animals and humans in the generation of serialposition curves for list learning.

\section{REFERENCES}

AtKinson, R. C., \& Shiffrin, R. M. (1968). Human memory: A proposed system and its control processes. In K. W. Spence \& J. T. Spence (Eds.), The psychology of learning and motivation: (Vol. 2). Advances in research and theory. New York: Academic Press.

Brown, A. L. (1974). The role of strategic behavior in retardate memory. In N. R. Ellis (Ed.), International review of research in mental retardation (Vol. 7). New York: Academic Press.

Davis, R. T., \& FrtTs, S. S. (1976). Memory and coping processes in discrimination learning. In D. L. Medin, W. A. Roberts, \& R. T. Davis (Eds.), Processes of animal memory. Hillsdale, NJ: Erlbaum.

DiMatTIA, B. V., \& KeSNER, R. P. (in press). Serial position curves in rats: Automatic vs controlled information processing. Journal of $E x-$ perimental Psychology: Animal Behavior Processes.

Donaldson, W., \& Glathe, H. (1969). Recognition memory for item and order information. Journal of Experimental Psychology, 82, $557-560$.

EвENноLтZ, S. M. (1972). Serial learning and dimensional organization. In G. H. Bower (Ed.), The psychology of learning and motivation (Vol. 5, pp. 267-314). New York: Academic Press.

Foucault, M. (1928), Les inhibitions internes de fixation. Annee Psychologique, 29, 92-112.

GafFan, D., \& Weiskrantz, L. (1980). Recency effects and lesion effects in delayed non-matching to randomly baited samples by monkeys. Brain Research, 196, 373-386.

Glanzer, M., \& Cunitz, A. R. (1966). Two storage mechanisms in free recall. Joumal of Verbal Learning and Verbal Behavior, 5, 351-360.

HASHER, L., \& ZACKS, R. T. (1979). Automatic and effortful processes in memory. Journal of Experimental Psychology: General, 108, 356-388.

KESNER, R. P. (1984). The neurobiology of memory: Implicit and explicit assumptions. In J. L. McGaugh, G. Lynch, \& N. M. Weinberger (Eds.), Neurobiology of learning and memory. New York: Guilford Press.

Kesner, R. P., \& DiMattia, B. V. (in press). Posterior parietal association cortex and hippocampus: Equivalency of mnemonic function in animals and humans. In L. R. Squire \& N. Butters (Eds.), Neuropsychology of memory. New York: Guilford Press.

KESNER, R. P., \& Novak, J. (1982). Serial position curve in rats: Role of the dorsal hippocampus. Science, 218, 173-174.

Kinsbourne, M., WoOD, F. (1982). Theoretical considerations regarding the episodic-semantic memory distinction. In $\mathrm{L}$. S. Cermak (Ed.), Human memory and amnesia. Hillsdale, NJ: Erlbaum.

MELTON, A. W. (1963). Implications of short-term memory for a general theory of memory. Journal of Verbal Learning and Verbal Behavior, 2, 1-21

Murdock, B. ${ }^{-}$B., JR. (1960). TThe distinctiveness of stimuli. Psychological Review, 67, 16-31.

MURDOCK, B. B., JR. (1962). The serial position effect in free recall. Journal of Experimental Psychology, 64, 482-488.

MURDOCK, B. B. JR. (1968). Modality effects in short-term memory: Storage or retrieval? Journal of Experimental Psychology, 77, 79-86.

Norman, D. A., \& WICKELGREN, W. A. (1965). Short-term recognition memory for single digits and pairs of digits. Journal of Experimental Psychology, 70, 479-489.

Olton, D. S., Collison, C., \& Werz, M. A. (1977). Spatial memory and radial arm maze performance of rats. Learning and Motivation, 8, 289-314.

Olton, D. S., \& SAMUELSON, R. J. (1976). Remembrance of places passed: Spatial discrimination and response inhibition. Joumal of Experimental Psychology: Animal Behavior Processes, 2, 97-116.

POSNER, M. I., \& SNYDER, C. R. R. (1975). Attention and cognitive control. In R. L. Solso (Ed.), Information processing and cognition: The Loyola Symposium. Hillsdale, NJ: Erlbaum.

RoberTS, W. A., \& KRAEMER, P. J. (1981). Recognition memory for lists of visual stimuli in monkeys and humans. Animal Learning \& Behavior, 9, 587-594.

Roberts, W. A., \& SMythe, W. E. (1979). Memory for lists of spatial events in the rat. Learning and Motivation, 10, 313-336.

SANDS, S. F., \& WRIGHT, A. A. (1980). Primate memory: Retention of 
serial list items by a rhesus monkey. Science, 209, 938-939.

SHIFFrin, R. M., \& ScHNEIDER, W. (1977). Controlled and automatic human information processing: II. Perceptual learning, automatic attending, and a general theory. Psychological Review, 84, 127-190.

SHIMP, C. P. (1976). Short-term memory in the pigeon: Relative recency. Journal of the Experimental Analysis of Behavior, 25, 55-61.

Thompson, R. K. R., \& Herman, L. M. (1977). Memory for lists of sounds by the bottle-nosed dolphin: Convergence of memory processes with humans? Science, 195, 501-503.

Tulving, E. (1968). Theoretical issues in free recall. In T. R. Dixon
\& D. L. Horton (Eds.), Verbal behavior and general behavior theory. Englewood Cliffs, NJ: Prentice-Hall.

WAUGH, N. C. (1960). Serial position and the memory span. American Journal of Psychology, 73, 68-79.

WHITLOW, J. W. (1975). Short-term memory in habituation and dishabituation. Journal of Experimental Psychology: Animal Behavior Processes, 3, 93-97.

(Manuscript received June 1, 1983;

revision accepted for publication April 27, 1984.) 